\title{
Pharmacokinetics of Lopinavir Determined with an ELISA Test in Youths with Perinatally Acquired HIV
}

\author{
Roberta Prinapori • Raffaella Rosso • Antonio Di Biagio • Franca Miletich • Elisa Furfaro • \\ Lucia Taramasso • Francesca Ginocchio • Vania Giacomet • Loredana Nulvesu • \\ Maria Pia Sormani • Irene Schiavetti • Alessio Signori • Laura De Hoffer • Claudio Viscoli
}

Received: 13 March 2013 / Accepted: 24 July 2013 / Published online: 7 September 2013

(C) Dr. K C Chaudhuri Foundation 2013

\begin{abstract}
Objective To investigate the plasma levels of lopinavir by enzyme-linked immunosorbent assay (ELISA) in a cohort of patients who were vertically infected with human immunodeficiency virus 1 (HIV).

Methods Plasma levels of lopinavir $\left(\mathrm{C}_{\min }\right)$ were determined by ELISA test in patients treated with lopinavir/ritonavir-based combined antiretroviral therapy who had achieved virological response after $4 \mathrm{wk}$ of therapy. Reference lopinavir concentrations were $\mathrm{C}_{\min } 1-8 \mu \mathrm{g} / \mathrm{mL}$. Correlation between lopinavir plasma concentration and continuous variables was evaluated by mean of Pearson correlation coefficient. Differences in lopinavir (LPV) concentration for binary categorical variables were assessed by Mann-Whitney test, while for variables with more than two categories Kruskal-Wallis test was used.

Results Thirty-four patients were enroled; median age was 133 mo (15-265). The median lopinavir dose tested was $383.5 \mathrm{mg} / \mathrm{kg}$ (IQR: $266.6-400 \mathrm{mg} / \mathrm{kg}$ ), with a median plasma concentration of $8.8 \mu \mathrm{g} / \mathrm{mL}$ (IQR: $5-14 \mu \mathrm{g} / \mathrm{mL}$ ). Lopinavir $\mathrm{C}_{\text {min }}$ was $<1 \mu \mathrm{g} / \mathrm{mL}$ in only one sample $(2.9 \%)$, while 14 samples had $\mathrm{C}_{\text {min }}$ between 1 and $8 \mu \mathrm{g} / \mathrm{mL}(41.2 \%)$ and 19 $(55.9 \%)>8 \mu \mathrm{g} / \mathrm{mL}$. No significant correlations were found
\end{abstract}

R. Prinapori $\cdot$ R. Rosso $\cdot$ A. Di Biagio $\cdot$ F. Miletich $\cdot$ E. Furfaro $\cdot$ L. Taramasso $\cdot$ F. Ginocchio $\cdot$ L. Nulvesu $\cdot$ L. De Hoffer $\cdot$ C. Viscoli Infectious Diseases Clinic, San Martino Hospital, University of Genoa, Genoa, Italy

V. Giacomet

Luigi Sacco Hospital, University of Milan, Milano, Italy

M. P. Sormani $\cdot$ I. Schiavetti $\cdot$ A. Signori Section of Biostatistics, Department of Health Sciences, University of Genoa, Genoa, Italy

A. Di Biagio $(\square)$

Clinica Malattie Infettive, IRCCS Azienda Ospedaliera Universitaria

San Martino - IST, Genova 16132, Italy

e-mail: antonio.dibiagio@hsanmartino.it between plasma concentrations of lopinavir and the continuous variables considered in the study. A negative but, not completely significant, correlation was found between plasma drug concentration and body mass index $(r=-0.29 ; p=0.09)$. Conclusions The use of a simple and relatively cost-effective methodology might render therapeutic drug monitoring (TDM) appeal in the daily clinical practice.

Keywords Lopinavir/Ritonavir · Vertical transmission . Therapeutic drug monitoring $\cdot$ ELISA-TDM $\cdot$ HIV-infected patients $\cdot$ Adherence to cART

\section{Introduction}

The therapeutic drug monitoring (TDM) is a tool generally used to monitor plasma drug levels of antiretroviral drugs, being the plasma concentration of protease inhibitors (PIs) and non-nucleosidic reverse transcriptase inhibitors (NNRTIs) associated with the levels of viral suppression and drug toxicity. Unfortunately data about pharmacokinetics of these drugs in pediatric patients are limited [1,2].

TDM is also applicable to measure the adherence to the therapy, allowing to check if the medication is actually taken by the patient. United States and Europe HIV treatment guidelines recognize the potential benefit of TDM in selected groups of patients, including children, pregnant women, patients with a change in physiologic state, potential for drugdrug or food interaction, use of alternative dosage or drug related toxicity $[3,4]$.

However, the standard TDM methodology, the high performance liquid chromatography (HPLC), is expensive and technically-demanding. An alternative method to check concentrations of the drugs in plasma samples is by enzymelinked immunosorbent assay (ELISA)-TDM, cheaper and easier to perform than HPLC. The aim of the study was to 
evaluate the plasma levels of lopinavir (LPV) by TDMELISA in a cohort of vertically HIV-infected patients.

\section{Material and Methods}

This was an open-label and descriptive study in children, adolescents and young adults perinatally infected with HIV1. The authors defined children as those younger than $12 \mathrm{y}$, adolescents 12 to $18 \mathrm{y}$ and the young adults older than $18 \mathrm{y}$. All patients who had achieved virological response after $4 \mathrm{wk}$ of combined antiretroviral therapy (cART) containing LPV/ ritonavir plus two nucleoside reverse transciptase inhibitors (NRTIs) were included in the study. Virological response was defined as viral load (VL) $<50$ copies $/ \mathrm{mL}$ or decrease of $>1$ $\log _{10}$ in the first $4 \mathrm{wk}$ of treatment.

Blood samples $(5-7 \mathrm{~mL})$ for pharmacokinetic evaluation were drawn in EDTA-containing tubes. At the time of the sample collection the patients, helped from parents or legal guardians, filled an adherence questionnaire regarding adherence during the last $4 \mathrm{~d}$, modality of drugs consumption (empty/full stomach, with adequate water intake), concomitant medication, compliance to the therapeutic schedule.

In adolescents and young adults weighing more than $40 \mathrm{~kg}$, dosage of LPV/ritonavir was 400/100 mg twice daily; in children, $230 \mathrm{mg} / 57.5 \mathrm{mg} \mathrm{LPV} / \mathrm{r} / \mathrm{m}^{2}$ of body surface area per dose twice daily.

LPV $\mathrm{C}_{\min }$, were determined $4 \mathrm{wk}$ after the initiation of the therapy, to ensure steady-state plasma concentrations and all samples were collected $30 \mathrm{~min}$ before the morning dose of LPV/ritonavir (pre-dose). LPV $\mathrm{C}_{\min }$ were evaluated with TDM ELISA, an immunoenzymatic test (Lopinavir TDMELISA $^{\circledR}$, by Biostrands srl, Trieste, Italy), according to the procedures described below and detailed in the lopinavir TDM ELISA package insert [5]. TDM-ELISA technology is based on a competition between the drug in plasma sample and an analogue conjugated to the detecting enzyme. A species-specific solid phase captures the specific antibody, while excess sample and reagents are removed by washing. The conjugate bound to the solid phase is detected by adding a chromogen solution. The enzymatic activity produces a colored solution whose adsorbance can be read by a microplate reader at $450 \mathrm{~nm}$. Absorbance values are inversely proportional to the drug concentration on the sample. A calibration curve is tested in exactly the same way, with the following concentrations: $-0.625 \mu \mathrm{g} / \mathrm{mL},-2.5 \mu \mathrm{g} / \mathrm{mL},-6.25 \mu \mathrm{g} / \mathrm{mL}$, $-12.5 \mu \mathrm{g} / \mathrm{mL},-25 \mu \mathrm{g} / \mathrm{mL},-50 \mu \mathrm{g} / \mathrm{mL}$; negative plasma samples were included, the standard 0 was total binding. The dynamic range for the LPV test is 1 to $8 \mu \mathrm{g} / \mathrm{mL}$.

Statistical analysis was completed both for the real LPV plasma concentration and for the LPV plasma concentration divided in two classes $(<=8 \mu \mathrm{g} / \mathrm{mL}$ and $>8 \mu \mathrm{g} / \mathrm{mL})$.
Correlation between continuous LPV plasma concentration and continuous variables such as age in months, disease duration, weight, body mass index (BMI), lymphocyte CD4 cell count, drug dosage, time between last dose and sampling was evaluated by mean of Pearson correlation coefficient while for number of tablets, Spearman's rank correlation coefficient was used.

Differences in LPV concentration for binary categorical variables were assessed by mean of non-parametric MannWhitney test, while for categorical variables with more than two categories (i.e., : formulation) non-parametric KruskalWallis test was used.

The study protocol was approved by the local Institutional Review Board of participating centres. Written informed consent was obtained before study entry, and human experimentation guidelines of the US Department of Health and Human Services and/or those of the authors' institutions were followed.

\section{Results}

In one year of observation, a total of 34 HIV-infected young patients naïve to LPV were enroled in the study. Twenty-five patients (73.5 \%) were Caucasians, 4 (11.8\%) were Africans, 4 (11,8 \%) were Latin Americans, and 1 (2.9\%) was Asian. All patients showed good immuno-virological response to LPV-containing cART, with a decrease in viral load of $\geq 1$ $\log _{10}$ in the first $4 \mathrm{wk}$ of treatment. According to the Centers for Disease Control classification, 13 (38.2 \%) samples were collected in patients who were in stage $\mathrm{A}(\mathrm{A} 1=5 ; \mathrm{A} 2=5$ and $\mathrm{A} 3=3), 14(41.2 \%)$ were in stage $\mathrm{B}(\mathrm{B} 1=5 ; \mathrm{B} 2=5$ and $\mathrm{B} 3=4), 6(17.6 \%)$ in stage $\mathrm{C}(\mathrm{C} 2=1$ and $\mathrm{C} 3=5)$ and 1 $(3 \%)$ in stage $\mathrm{N}(\mathrm{N} 2)$. The median age of patients was 133 mo $(r=15-264 \mathrm{mo})$ and the weight ranges comprised between 11 and $76 \mathrm{~kg}$ with median weight of $34.1 \mathrm{~kg}$ (IQR: 24.3-52), and median BMI of $17.6 \mathrm{~kg} / \mathrm{cm}^{2}$ (IQR 16.2-20), as showed in Table 1.

All patients received LPV in twice-daily regimen; tablet formulation in 18 cases $(53 \%)$, capsules in $7(20.6 \%)$ and syrup in $9(26.4 \%)$. A variety of antiretroviral combinations were co-administered with LPV, including zidovudine/ lamivudine in 10 patients $(29.4 \%)$, tenofovir/lamivudine in $6(17.6 \%)$, abacavir/lamivudine in $6(17.6 \%)$, tenofovir/ emtricitabine in $5(14.7 \%)$ and other regimens in the remaining seven patients ( $20.6 \%)$.

The median time between last LPV dose and sample collection was $12.5 \mathrm{~h}$ (IQR: $12-13 \mathrm{~h}$ ) and median LPV dose tested was $383.5 \mathrm{mg} / \mathrm{m}^{2}$ (IQR: $266.6-400 \mathrm{mg} / \mathrm{m}^{2}$ ), with a median plasma concentration of $8.8 \mu \mathrm{g} / \mathrm{mL}$ (IQR: $5-14 \mu \mathrm{g} /$ $\mathrm{mL}$ ). LPV plasma concentrations resulted erratic, with big inter-patient variability: the average LPV $\mathrm{C}_{\min }$ of the cohort was $9.2 \mu \mathrm{g} / \mathrm{mL}(\mathrm{SD}= \pm 4.96, r=0.6-18 \mu \mathrm{g} / \mathrm{mL})$; in patients 
Table 1 Demographic and clinical data of the study population at baseline

\begin{tabular}{lll}
\hline Variable & Median & Range \\
\hline Gender - no. (\%) & & \\
$\quad$ Males 16 (45.7) & - & - \\
$\quad$ Female 19 (54.3) & - & - \\
Age (mo) & 133 & $15-265$ \\
Weight $(\mathrm{kg})$ & 31 & $11-76$ \\
BMI & 17 & $12-28$ \\
CD4+ (cells $\left./ \mathrm{mm}^{3}\right)$ & 569 & $258-1,945$ \\
CD4+\% & 28 & $16-45$ \\
Viral load $(\mathrm{copies} / \mathrm{mL})$ & $<50$ & $<40-33,000$ \\
LPV dosage $(\mathrm{mg} / \mathrm{kg})$ & 368 & $200-800$ \\
LPV C & 8.2 & $0.6-35.0$ \\
\hline
\end{tabular}

$B M I$ Body mass index, $L P V$ Lopinavir

reporting complete adherence average LPV $\mathrm{C}_{\min }$ was $9.8 \mu \mathrm{g} /$ $\mathrm{mL}(\mathrm{SD}= \pm 4.94 ; r=0.6-18 \mu \mathrm{g} / \mathrm{mL})$.

Among the 34 samples analyzed, $\mathrm{LPV} \mathrm{C}_{\min }$ was $<1 \mu \mathrm{g} / \mathrm{mL}$ in only one samples $\left(2.9 \%\right.$ ), while 14 samples had $\mathrm{C}_{\text {min }}$ between 1 and $8 \mu \mathrm{g} / \mathrm{mL}(41.2 \%)$ and $19(55.9 \%)>8 \mu \mathrm{g} / \mathrm{mL}$.

Six out of 34 patients referred at least one omission to therapy since the introduction of LPV in cART regimen, but none of them had LPV concentration $<1 \mu \mathrm{g} / \mathrm{mL}$. The adherence was complete in the remaining 28 cases $(82.4 \%)$, according to the results of the questionnaires filled by patients.

The only patient with LPV $\mathrm{C}_{\min }<1 \mu \mathrm{g} / \mathrm{mL}$ did not refer omissions and took the therapy on an empty stomach, the time between the last dose and the moment in which the sample was collected was $14 \mathrm{~h}$ in this case and the viremia was undetectable.

Nine patients had detectable viremia after 4 wk of LPV treatment; no significant correlations were found between plasmatic concentration of LPV and the other continuous variables considered in the study, such as age, length of infection, weight, BMI, lymphocyte CD4 cell count, dosage of LPV, time passed between last drug consumption and plasma sampling. A negative but, not completely significant, correlation was found between plasma drug concentration and BMI $(r=-0.29 ; p=0.09)$.

The non-parametric Kruskal Wallis test did not show statistically significant differences in LPV concentration among ethnicities $(p=0.340)$.

Higher LPV concentrations ( $>8 \mu \mathrm{g} / \mathrm{mL}$ ) were found in the majority of patients (19/34). Among them 14 received lamivudine in the back-bone regimen, 9 received zidovudine, 5 tenofovir, 2 emtricitabine, 3 abacavir, 3 didanosine, 1 stavudine and 1 efavirenz,. A not completely significant difference $(p=0.09)$ was found between values of LPV plasma concentrations and assumption of didanosine (median : 14; IQR : 14 14.6) compared to patients who did not take this drug (median: 8.1; IQR: 4.7-11). However only three of the patients enroled in the study ( $8.8 \%$ ) took didanosine. No statistically significant correlation was found between hours between taking of LPV and blood sampling and LPV concentration. Considering only subjects with a strict criteria of $12 \mathrm{~h}$ of taking LPV/r, there are 15 patients with a mean LPV plasma concentration of $8.71 \pm 4.65$, as shown in Fig. 1. Also in this
Fig. 1 LPV concentrations in samples and hour of collection (only considering a subgroup of 15 patients)

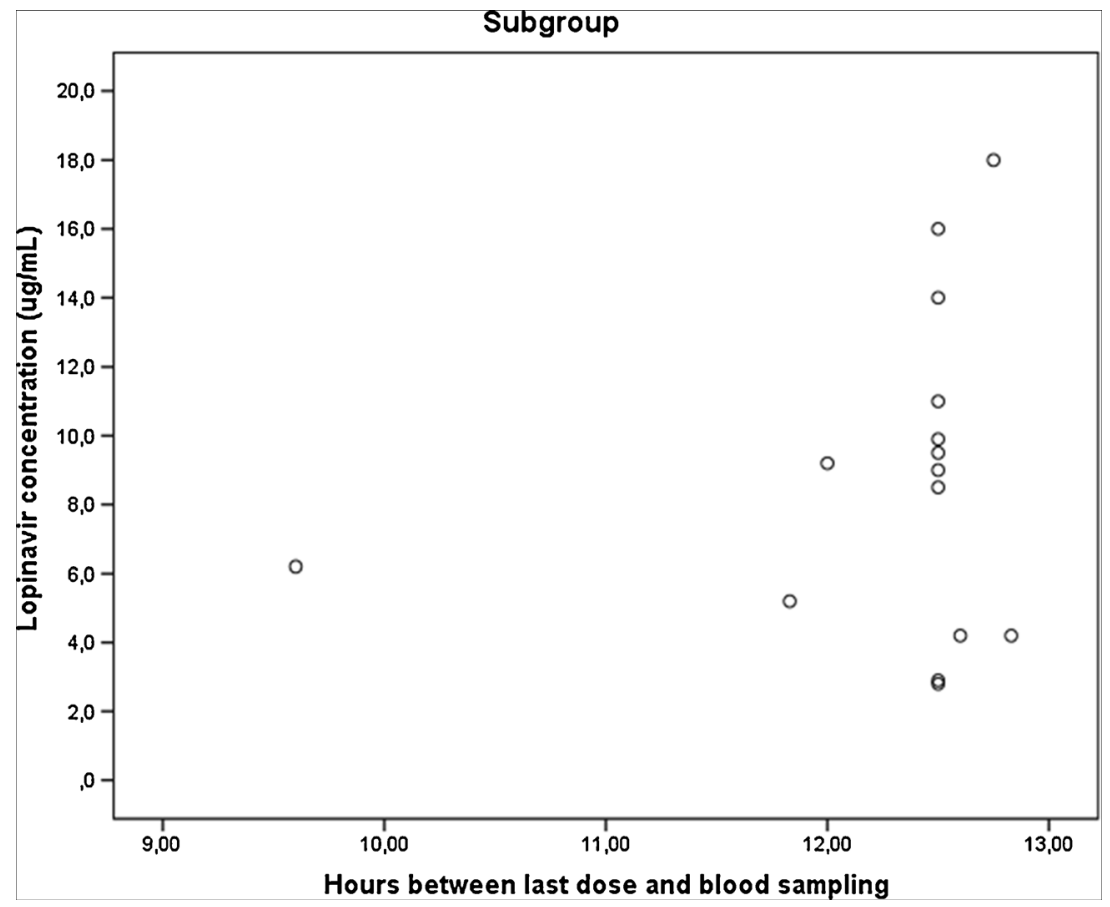


small subgroup, correlation between continuous LPV plasma concentration and time between last dose and sampling as assessed by mean of Pearson correlation coefficient did not reveal any statistical significance $(r=0.192 ; p=0.49)$.

\section{Discussion}

International, European, and US pediatric antiretroviral therapy guidelines recommend co-formulated protease inhibitor lopinavir/ritonavir as a first-line PI agent for the treatment of HIV infection in children and infants with a post-natal age of at least $14 \mathrm{~d}[4,6-8]$. The recommended doses for children who weigh more than $15 \mathrm{~kg}$ are $10 \mathrm{mg} / \mathrm{kg}$ of body weight or $230 \mathrm{mg} / \mathrm{m}^{2}$ (body surface area) twice daily, with a maximum of $400 \mathrm{mg}$ per dose unless it is combined with drugs affecting cytochrome (CYP) P450 metabolism, which require LPV dose adjustment [4].

Models of pharmacokinetics of LPV in children have been developed on the basis of weight and age of patients [9-12]. However, the absolute bioavailability of LPV co-formulated with ritonavir in humans has not yet been established [13].

A variety of factors can interact with LPV plasma concentration. The administration of the drug with a moderate fatty food for example may increase its adsorption [13].

Conversely, a factor potentially causing a decrease in plasma LPV concentrations is its hepatic inactivation made by the cytochrome CYP $3 \mathrm{~A} 4$, partially inhibited by ritonavir coformulation.

Another factor influencing the kinetics of the drug is its high plasma protein binding: at steady state, LPV is $98-99 \%$ plasma protein bound, involving possible interactions with a multitude of drugs binding plasma proteins too.

In the index study, no patient took other drugs or had comorbidities affecting the ability to metabolize the drug. However, from the analysis, inter-individual variability in drug concentration resulted high and no factor associated significantly with drug concentration was found. These data led the authors to think that therapeutic drug monitoring should have a relevant role in routine monitoring of patients taking LPV.

The use of TDM in the management of patients infected with HIV has been widely studied, and well accepted by the patients [14-18]. TDM is a valid clinical method to avoid over or under-dosage of drugs and also to monitor compliance, in order to optimize the treatment for each patient and avoid side effects.

Besides, it could also be a useful tool to monitor which patients may be eligible for once-daily drug regimens [19]. Nevertheless, few data are available on TDM use in children and adolescents $[12,18,20,21]$. High performance liquid chromatographic method remains the standard of care in TDM, but it is a technically-demanding and time consuming procedure, available in few laboratories and run by specifically trained expert personnel. The TDM ELISA method overcomes problems associated with peripheral HIV centers' lacking of access to pharmacokinetic test.

High inter-individual variability in trough levels of LPV was found, as already observed in all patients treated with PIs [22].

In patients with a difficult approach to cART, such as children, adolescents and young adults, TDM may also have a role in monitoring adherence during routine clinical practice. In fact, the adherence to HIV medication regimens is often suboptimal in young patients and decreases progressively when children reach adolescence, [23-26] due to a multitude of factors, such as lack of family support, denial and fear of HIV infection, lack of belief in the effectiveness of medications, regimen fatigue, adverse effects and fear of stigmatization [25, 27-32].

The main limitations of the present study were the small size of study population, the exclusion of patients which did not meet the criteria for viral response and those pre-treated with other PIs. Furthermore, the results were not compared with the gold standard TDM methodology represented by HPLC.

The use of a simple and relatively cost-effective methodology might render TDM feasible in the daily clinical practice of HIV-infected youths.

\section{Conclusions}

TDM ELISA testing could be a reliable and useful method for routine monitoring of drug plasma levels, since it is easy to perform in any laboratory and could be a valid clinical tool to avoid over or under-dosage of drugs and also to monitor compliance, in order to optimize the treatment for each patient and avoid side effects.

Acknowledgments The authors are indebted to Professor PierLuigi Navarra, for encouraging the continuation of the paper. They would also like to thank the children and their parents/ legal guardians for their participation to the study.

Contributions RR passed away during the development of this manuscript. She reviewed the outline and first draft in detail for clinical accuracy and intellectual content. AD, RR, RP, VG, FG, LT, FM, EF, LN had full access to all the data in the study and take responsibility for the integrity of the data and the accuracy of the data analysis. AD, RR: Study concept and design; MS, AS, IS: Statistical expertise; AD, RP, CV, LT: Drafting of the manuscript; LD, RP, LT: Critical revision of the manuscript for important intellectual content. All authors approved the final version of the manuscript.

Conflict of Interest The authors did not receive any financial support for their contribution to this study, but $\mathrm{AD}$ has received prior research funding and/or consultancy honoraria from Abbott, Bristol Myers Squibb, Gilead, Janssen-Cilag, Merck Sharp \& Dohme, Roche, and ViiV. 
Role of Funding Source The study was supported by Programma Nazionale di Ricerca sull'AIDS, Istituto Superiore di Sanità, Italy, Grants 30F/06. Codice Eudract 2007-00389638 "Studio di farmacocinetica e farmacodinamica nella ottimizzazione della terapia antiretrovirale".

\section{References}

1. Fraaij PL, Rakhmanina N, Burger DM, de Groot R. Therapeutic drug monitoring in children with HIV/AIDS. Ther Drug Monit. 2004;26:122-6.

2. Nso AP, Larru B, Bellón JM, Mellado MJ, Ramos JT, González MI, et al. Comparison of levels of antiretroviral drugs with efficacy in children with HIV infection. Indian J Pediatr. 2010;77:397-402.

3. Aarnouste RE, Schapiro JM, Boucher CA, Hekster YA, Burger DM. Therapeutic drug monitoring: An aid to optimizing response to antiretroviral drugs? Drugs. 2003;63:741-53.

4. US Department of Health and Human Services, Panel on Antiretroviral Therapy and Medical Management of HIV Infected Children. Guidelines for the use of antiretroviral agents in pediatric HIV infection. Available at: http://www.aidsinfo.nih.gov/contentfiles/ lvguidelines/pediatricguidelines.pdf. Updated November 5, 2012.

5. TDM-ELISA Lopinavir. Package insert and operative instructions. 2010. Retrieved from: www.biostrands.com.

6. World Health Organization. Antiretroviral therapy of HIV infection in infants and children: towards universal access: recommendations for a public health approach 2010 revision. Geneva, Switzerland: WHO; 2010. Available at: http://whqlibdoc.who.int/publications/ 2010/9789241599801_eng.pdf.

7. PENTA Steering Committee. Paediatric European network for treatment of AIDS response to 2010 revision of World Health Organization recommendations on 'antiretroviral therapy for HIV infection in infants and children'. HIV Med. 2011;12:385-6.

8. Lodha R, Mangiani M. Antiretroviral therapy in children: Recent advances. Indian J Pediatr. 2012;79:1625-33.

9. Hsu A, Isaacson J, Brun S, Bernstein B, Lam W, Bertz R, et al. Pharmacokinetic-pharmacodynamic analysis of lopinavir/ritonavir in combination with efavirenz and two nucleoside reverse transcriptase inhibitors in extensively pretreated human immunodeficiency virus infected patients. Antimicrob Agents Chemother. 2003;47:350-9.

10. Jullien V, Urien S, Hirt D, Delaugerre C, Rey E, Teglas JP, et al. Population analysis of weight-, age-, and sex-related differences in the pharmacokinetics of lopinavir in children from birth to 18 years. Antimicrob Agents Chemother. 2006;50:3548-55.

11. Podzamczer D, King MS, Klein CE, Flexner C, Katlama C, Havlir $\mathrm{DV}$, et al. High-dose lopinavir/ritonavir in highly treatmentexperienced HIV-1 patients: Efficacy, safety, and predictors of response. HIV Clin Trials. 2007;8:193-204.

12. Rakhmanina $\mathrm{N}$, van den Anker J, Baghdassarian A, Soldin S, Williams K, Neely MN. Population pharmacokinetics of lopinavir predict suboptimal therapeutic concentrations in treatment-experienced human immunodeficiency virus-infected children. Antimicrob Agents Chemother. 2009;53:2532-8.

13. Kaletra product labeling [package insert]. North Chicago, IL: Abbott Laboratories; Available at: http://dailymed.nlm.nih.gov/dailymed/ archives/fdaDrugInfo.cfm?archiveid=1584.

14. Acosta EP, Gerber JG; Adult Pharmacology Committee of the AIDS Clinical Trials Group. Position paper on therapeutic drugmonitoring of antiretroviral agents. AIDS Res Hum Retroviruses. 2002;18:825-34.

15. Back D, Gatti G, Fletcher C, Garaffo R, Haubrich R, Hoetelmans R, et al. Therapeutic drug monitoring in HIV infection: Current status and future directions. AIDS. 2002;16:S5-37.
16. Bastiani E, Benedetti F, Berti F, Campaner P, Donadel E, Montagna M, et al. Development and evaluation of an immunoassay for the monitoring of the anti-HIV drug Amprenavir. J Immunol Methods. 2007;325:35-41.

17. Uglietti A, Ravasi G, Meroni V, Narciso P, Ladisa N, Martini S, et al. Nelfinavir+M8 plasma levels determined with an ELISA test in HIV infected patients with or without HCV and/or HBV coinfection: The VIRAKINETICS II study. Curr HIV Res. 2009;7:293-301.

18. Rakhmanina NY, van den Anker JN, Soldin SJ, van Schaik RH, Mordwinkin N, Neely MN. Can therapeutic drug monitoring improve pharmacotherapy of HIV infection in adolescents? Ther Drug Monit. 2010;32:273-81.

19. Rosso R, Di Biagio A, Dentone C, Gattinara GC, Martino AM, Viganò $\mathrm{A}$, et al. Lopinavir/ritonavir exposure in treatment-naive HIV-infected children following twice or once daily administration. J Antimicrob Chemother. 2006;57:1168-71.

20. Best BM, Capparelli EV, Diep H, Rossi SS, Farrell MJ, Williams E, et al. Pharmacokinetics of lopinavir/ritonavir crushed versus whole tablets in children. J Acquir Immune Defic Syndr. 2011;58:385-91.

21. Van Rossum AM, Bergshoeff AS, Fraaij PL, Hugen PW, Hartwig NG, Geelen SP, et al. Therapeutic drug monitoring of indinavir and nelfinavir to assess adherence to therapy in human immunodeficiency virus-infected children. Pediatr Infect Dis J. 2002;21:743-7.

22. Gatti G, Castelli-Gattinara G, Cruciani M, Bernardi S, De Pascalis CR, Pontali E, et al. Pharmacokinetics and pharmacodynamics of nelfinavir administered twice or thrice daily to human immunodeficiency virus type 1-infected children. Clin Infect Dis. 2003;36:1476-82.

23. Battles H, Wiener L. From adolescence through young adulthood psychosocial adjustment associated with long-term survival of HIV. J Adolesc Health. 2002;30:161-8.

24. Mellins C, Brackis-Cott E, Dolezal C, Abrams E. The role of psychosocial and family factors in adherence to antiretroviral treatment in human immunodeficiency virus-infected children. Pediatr Infect Dis J. 2004;23:1035-41.

25. Murphy DA, Wilson CM, Durako SJ, Muenz LR, Belzer M, Adolescent Medicine HIV/AIDS Research Network. Antiretroviral medication adherence among the REACH-HIV-infected adolescent cohort in the USA. AIDS Care. 2001;13:27-40.

26. Williams PL, Storm D, Montepiedra G, Nichols S, Kammerer B, Sirois PA, et al. Predictors of adherence to antiretroviral medications in children and adolescents with HIV infection. Pediatrics. 2006;118:1745-57.

27. Biadgilign S, Deribew A, Amberbir A, Deribe K. Adherence to highly active antiretroviral therapy and its correlates among HIV infected pediatric patients in Ethiopia. BMC Pediatr. 2008;8:53.

28. Giannattasio A, Albano F, Giacomet V, Guarino A. The changing pattern of adherence to antiretroviral therapy assessed at two time points, 12 months apart, in a cohort of HIV-infected children. Expert Opin Pharmacother. 2009;10:2773-8.

29. Marhefka SL, Farley JJ, Rodrigue JR, Sandrik LL, Sleasman JW, Tepper VJ. Clinical assessment of medication adherence among HIVinfected children: examination of the Treatment Interview Protocol (TIP). AIDS Care. 2004;3:323-38.

30. Merzel C, Vandevanter N, Irvine M. Adherence to antiretroviral therapy among older children and adolescents with HIV: a qualitative study of psychosocial contexts. AIDS Patient Care STDS. 2009;22:977-87.

31. Rosso R, Di Biagio A, Maggiolo F, Nulvesu L, Callegaro AP, Taramasso L, et al. Patient-reported outcomes and low-level residual HIV-RNA in adolescents perinatally infected with HIV-1 after switching to one-pill fixed-dose regimen. AIDS Care. 2012;24:54-8.

32. van der Flier M, Verweel G, van der Knaap LC, van Jaarsveld P, Driessen GJ, van der Lee M, et al. Pharmacokinetics of lopinavir in HIV type-1-infected children taking the new tablet formulation once daily. Antivir Ther. 2008;13:1087-90. 